therefore, be other kinds of nidus to harbour the larvæ of Musca domestica through the winter.

Monreith. Herbert Maxwell.

The Magnetic Storm of August 11-12, 1919.

THE Kodaikanal Observatory magnetographs recorded the "sudden commencement" of this storm on August Ir at $6 \mathrm{~h} .58 \mathrm{~m}$. G.M.T., horizontal force showing an instantaneous rise of $\mathrm{I} 49 \gamma$ and vertical force about $35 \gamma$, while the declination magnet was deflected about $I^{\prime}$ towards west. I have measured the three traces, and, after making due allowance for the errors affecting the hour-marks, the following values were obtained :-

$\begin{array}{llllc}\text { Horizontal force } & \ldots & \ldots & 6 & 5^{8 \cdot o} \\ \text { Vertical force } & \ldots & \ldots & 6 & 5^{8 \cdot 7} \\ \text { Declination } \ldots & \ldots & \ldots & 6 & 57 \cdot 9\end{array}$

Greater weight may be given to the declination result because of the more sharply defined hour-marks in this trace.

It is of interest to compare this result with the times recorded in England in view of the fact that at Kodaikanal the sun at 6 h. $58 \mathrm{~m}$. G.M.T. was barely three minutes past meridian passage and only $5^{\circ}$ north of the zenith. In other words, this observatory was almost at the centre of the earth's disc as seen from the sun, and it might be supposed that the disturbance would have been recorded here earlier than at other places if it is directly due to emanations from the sun.

Apparently the sudden commencement was recorded at Kew "at about 7 h. G.M.'T.," and at Stonyhurst at 6h. 50m., while at Eskdalemuir the time is given definitely as $6 \mathrm{~h} .58 \mathrm{~m}$., in exact agreement with my result (N.ATURE, vol. ciii., pp. 483,505 and 506).

It seems probable that the impulse is simultaneous over the earth to within a fraction of a minute, but it would be interesting to know the limits of error to which the above times are subject, and particularly whether allowance has been made for the rather large error which may be produced by the mechanism for cutting off the light from the sensitive paper at each hour.

Kodaikanal, S. India, November 25 . J. Evershed.

\section{Deflection of Light during a Solar Eclipse.}

During a total eclipse of the sun there will be, as I suppose, an increase of density of the air at the central portion of the shadow. If we imagine the normal atmosphere removed, we are left with a residual atmosphere the refraction effects of which will be changes in the normal refraction effects. The whole point is whether, on reasonable suppositions, this residual atmosphere can produce refraction effects of the order of the observed effects that have been attributed to the gravitational field of the sun.

Let us suppose with Prof. Eddington that the portion of this residual atmosphere concerned corresponding to a star near the edge of the sun's disc has a radius of about $\mathrm{I}_{5} \mathrm{O}$ yards, and let the index of refraction of the residual atmosphere at the central part be $\mu_{2}$, and that at the circumference $\mu_{1}$. Then, as I have shown, the displacement will be accounted for if

$$
\mu_{2}=\mu_{1}\left(1+\frac{7}{10^{8}}\right) \text {. }
$$

Assuming that the change of density depends only on change of temperature, we have

$$
\rho_{2}=\frac{\theta_{2}}{\rho_{1}}=\frac{\mu_{2}-\mathrm{I}}{\theta_{1}}
$$

where $\rho_{2}, \rho_{1}, \theta_{2}, \theta_{1}$ are the increases of density and falls of temperature at the centre and circumference. NO. 26 I 8 , VOL. IO4]
Thus we have, approximately,

$$
\frac{\theta_{2}-\theta_{1}}{\theta_{2}}=\frac{7}{10^{8}\left(\mu_{2}-1\right)} ; \quad \theta_{2}-\theta_{1}=\frac{7}{\theta_{1}}=\frac{7}{10^{8}\left(\mu_{1}-1\right)} .
$$

We must now make some assumption as to the gradient of temperature, and this is a very important point. It would not, I think, be right to make it uniform or approximately uniform throughout a distance of 150 miles. We will assume that in a distance of ${ }^{1} 5^{\circ}$ yards the increase of temperature is I/ Iooth part of $\theta_{2}$. This does not seem to be unreasonable.

We then have $\mu_{2}=1 \cdot 000007$ for the index of refraction of the residual atmosphere at the centre, corresponding to a lowering of temperature of $6.28^{\circ} \mathrm{C}$. at the centre and of $6.22^{\circ} \mathrm{C}$. at a distance of 150 yards. If we assume that the increase of temperature at a distance of $I_{5} 0$ yards is $\mathrm{I} /$ roth of $\theta_{2}$, we get the fall at the centre $0.63^{\circ} \mathrm{C}$. and that at $\mathrm{x}_{5} \mathrm{0}$ yards' distance $0.57^{\circ} \mathrm{C}$. It will be seen that the greater $\frac{\theta_{2}-\theta_{1}}{\theta_{2}}$, the smaller is the necessary fall of temperature at the centre.

University College, Galway, December 28.

\section{Entente Scientific Literature in Central Europe during the War.}

I was much interested in reading Prof. Brauner's letter from Prague in Natuke of December II. Like Prof. Brauner, I was unable to obtain Nature during the first two years of the war, and I fully appreciate his joy on obtaining your invaluable journal again, after an interval of more than five years.

Prof. Brauner states that from July 30, 19I4, "the Austrian Government prohibited for more than four years the circulation of anything printed in England as a punishment for the regard which, especially during the war, we [the Czechs] have always had for your country."

This statement is misleading, for "enemy" periodicals were withheld from the whole of the Austrian Empire, and not from the Bohemians alone. Prof. Brauner is apparently unaware of the fact that, from I9I6 onwards, it was possible for institutes of the Austrian universities and technical high schools to obtain scientific periodicals and publications from Entente countries. The enactment which made this possible did not appear to be generally known, but I am aware of two institutions at least, which made application for, and obtained from the Austrian Foreign Office, the necessary permission; and in neither instance was any difficulty experienced.

The Radium Institute of Vienna was one of the institutions concerned, although at that time several Poles (one of them a Russian subject) and the writer of this letter were working there. What is more, the Austrian Foreign Office was not unaware of this "quasi-international" character of the Radium Institute!

Books were also obtainable, and I know of several men of science of Vienna, Budapest, and even of Prague, who were granted permission and obtained books from France and England through neutral countries.

$A$ few months before the armistice I remember sitting in a Viennese restaurant at the same table as a gentleman, who was voraciously devouring the contents of the Sketch and the Illusirated London Neres. To judge from his frequent unsuppressed laughter, one would have thought he was scanning the pages of Punch. Not having seen these periodicals for nearly five vears, my interest and curiosity were aroused, and I asked this gentleman's permission to 